\title{
Study on the Excavating Project Design of Main Slope in Dahaize Coal
}

\author{
Mine \\ Zhe Wang ${ }^{1.2}$, Hongtao $\mathrm{Hu}^{2}$, Shengqun $\mathrm{Wu}^{3}$ \\ ${ }^{1}$ Anhui University of Science and Technology, Huainan, 232001, China \\ ${ }^{2}$ Xiaohuigou Coal Mine Co.,LTD in Shanxi Province, Taiyuan, 030401, China \\ ${ }^{3}$ The First Hydrological Geological Team in Coal Geological Central Office of China, Handan, \\ 056004, China \\ a893553716@qq.com _ , b375014155@qq.com \\ ,271235256@qq.com
}

Keywords: Project design; Engineering geology; Hydrogeololgy; Slope excavating

Abstract: Dahaize coal mine was located in Maowusu desert and the buried depth of coal seam was relatively large. The excavated main slope passed through the following stratums, such as Quaternary, Jurassic, Cretaceous, and so on. And the differences of rock mechanics characteristic were very obviously. In the article, the constructed well bores were analyzed. The rock mechanics characteristics of each layer were traced out. The engineering geological parameters of each layer were calculated comprehensively and the rock mass quality classification was obtained. The monolayer water inflow of aquifer was predicted by the horizontal long and narrow water corridor method. The result provided the basis to choose the reasonable drainage facilities for shaft excavation. According to the analysis comprehensively of hydrogeology and engineering geology characteristics of each layer, the optimal scheme of slope excavating was established.

\section{Introduction}

Dahaize coal mine is located in the west of Yuyang district in Shanxi province and the coal field is located in the north of Yuheng mine district in Jurassic coal field belonging to the Shanxi north mapped out by government. The preliminary production capacity of mine is 30.0Mt/a.The development project is that slope serves as main shaft and vertical shaft as auxiliary shaft. The slope is drive from west to east with dip angle $14^{\circ}$ and the bottom is floor of $3 \#$ coal seam. The most optimal project is determined by carefully studying rock characteristics, engineering geology and hydrogeology characteristics.

\section{Lithology characters of shaft section}

\subsection{Stratum}

The geological characters of each stratum passed through by the shaft are exactly divided according to the well checking hole. The main slope excavation will pass through the Quaternary formation, the Luohe formation of lower Cretaceous and the Anding formation, Zhiluo formation and Yanan formation belonging to the middle Jurassic. Now introductions are as follows.

(1) Quaternary. Its lithology is light yellow sand and sandy clay, with the variation of the surface size larger. Its sorting, grinding roundness are poor. The lower is relatively good with sand dunes, ridges, loose structure. The length of quaternary passed through by the shaft ranges from0 to $81.36 \mathrm{~m}$. 
(2) Luohe formation of the lower Cretaceous. Its Lithology mainly includes the giant staggered lamellar grain sandstone, fine sandstone and thin siltstone. Its colors are reddish brown and purple red. Sand composition is mainly of quartz, feldspar, argillaceous and calcareous knot which is lax and well developed for cross bedding. The length of Luohe formation in the lower Cretaceous passed through by the shaft ranges from 81.36 to $1379.03 \mathrm{~m}$.

(3) Anding formation of the middle Jurassic. The seams are mainly the river sediments under semi-arid conditions, upper is purple-red and lumpy sandy mudstone, lower is middle-grain feldspar quartz sandstone with grey giant layer. The rock seam is poorly sorted, angular, porphyritic structure and tumor like lump sandstone projections. And it touches the Zhiluo formation completely. The length of Anding formation passed through by the shaft ranges from 1379.03 to $1532.76 \mathrm{~m}$.

(4) Zhiluo formation of the middle Jurassic. The strata belong to the river sediment under semi-arid conditions. Among the mineral lithology of rock shows that hoar fine-grained sandstone occupies first place, medium grained sandstone, dark grey sandy mudstone, mudstone and silt sandstone comes second. Local of rock contains coarse sandstone with large cross bedding. Sandstones are interbeded with mudstone for transition with no obvious stratification limits. And it contacts the Yan'an formation. The length of Zhiluo formation passed through by the shaft ranges from 1532.76 to $2482.73 \mathrm{~m}$.

(5) Yanan formation of the middle Jurassic. It is mainly coal-bearing stratum. The lithology is mainly a set of gray fine-grained sandstone, sandstone, dark gray mudstone, silt sandstone, deep gray mudstone and black carbonaceous mudstone, which is a series of fluvial and lacustrine sediments. Sandstone is the multi block structure and the texture is hard and dense. The strata length from Yanan formation to floor of 3\#coal passed through by the shaft ranges from 2482.73 to 2765.86m.

\subsection{Geological structure}

There is no relevant seismic data in the well bore area and the geological structure is not found in the construction of well bore. During the general survey, there are not large scale faults and folds, igneous activity in scope of two-dimensional seismic. Its geological structure is simple.

\section{Engineering geology characteristics of shaft section}

The engineering geology quantitative evaluations of wellhole surrounding rock are obtained by three methods which are recommended according to the "Mining Engineering Geology Exploration norms" (GB12719-1991).

(1) Rock quality level and rock RQD values integrity evaluation

(2) Rock mass coefficient ( $Z$ value)

$\mathrm{Z}=\mathrm{I} \cdot \mathrm{F} \cdot \mathrm{S}$

$\mathrm{S}=\mathrm{Rc} / 10$

(3) Rock Quality Index Method (M value)

$\mathrm{M}=\mathrm{Rc} \cdot \mathrm{I} / 30$

Where: Z-rock quality factor.

I- Rock complete coefficient(RQD value in dollars).

$\mathrm{F}-$ Structure surface friction coefficient.

$\mathrm{S}$ - Rock hard coefficient.

$\mathrm{Rc}-$ Rock saturation axial compressive strength, MPa.

$\mathrm{M}-$ Rock quality indicators.

Calculated results from the wellbore surrounding rock and rock quality grade of each quantitative 
evaluation are shown that: the integrity of rock from shallow to deep gradually changes for the better and in plagioclase $1901.91 \mathrm{~m}$ above bedrock segment mostly is moderately completed, under which is more than for the more completion. According to the evaluation of rock quality factor plagioclase rock mass rating above $761.71 \mathrm{~m}$ is very bad. The rock quality level of the segment with the length from 761.71 to $1083.35 \mathrm{~m}$ in cline is more general. According to rock quality evaluation of rock quality indicators in plagioclase $1083.35 \mathrm{~m}$ is poor, the lower is medium. Evaluation of the results of three rock mass quality is a basic agreement.

According to the "Hydrogeology and Engineering Geology mining exploration norms"(GB 12719-1991) and the "Engineering Classification of Rock"(GB50218-94), and refer to the lithological and rock saturated compressive strength geotechnical classification, the rock mass passed through by wellbore is divided into four major rock types and seven rock groups(Table 1).

Table 1 Rock and soil engineering geological classification

\begin{tabular}{|c|c|c|c|c|c|}
\hline \multicolumn{2}{|c|}{$\begin{array}{l}\text { Engineering geological } \\
\text { classification }\end{array}$} & \multirow[t]{2}{*}{ Strata } & \multirow{2}{*}{$\begin{array}{l}\text { Compressive } \\
\text { strength (MPa) }\end{array}$} & \multirow[t]{2}{*}{ Spatial distribution } & \multirow{2}{*}{$\begin{array}{l}\text { Rock } \\
\text { structure }\end{array}$} \\
\hline Rocks & Rock Quality & & & & \\
\hline \multirow[t]{2}{*}{$\begin{array}{l}\text { Very weak } \\
\text { rock }\end{array}$} & Very Inferior & Loose sand sets & Disintegration & $\begin{array}{l}\text { The distribution of whole } \\
\text { region, the eolian deposit } \\
\text { and the fluvial origin } \\
\text { District sporadic outcrops, } \\
\text { loose sand volts in the lower } \\
\text { group }\end{array}$ & $\begin{array}{l}\text { Granular } \\
\text { structure }\end{array}$ \\
\hline & Inferior & $\begin{array}{l}\text { Sandstone Group } \\
\text { of Luohe }\end{array}$ & $0.5 \sim 19.8$ & $\begin{array}{l}\text { Most of argillaceous } \\
\text { sandstone cemented Luohe } \\
\text { (easy to disintegrate) }\end{array}$ & $\begin{array}{c}\text { Block } \\
\text { structure }\end{array}$ \\
\hline \multirow[b]{2}{*}{ Soft Rock } & Inferior & $\begin{array}{l}\text { Coal and rock } \\
\text { group }\end{array}$ & $10.2 \sim 22.6$ & Yan'an & $\begin{array}{l}\text { Layered } \\
\text { structure }\end{array}$ \\
\hline & Inferior-medium & Mudstone group & $12.7 \sim 14.4$ & Anding, Zhiluo and Yan'an & $\begin{array}{l}\text { Layered } \\
\text { structure }\end{array}$ \\
\hline $\begin{array}{l}\text { Relatively } \\
\text { weak rock }\end{array}$ & Medium-good & $\begin{array}{l}\text { Sandy siltstone and } \\
\text { mudstone }\end{array}$ & $11.5 \sim 29.9$ & Anding, Zhiluo and Yan'an & $\begin{array}{l}\text { Layered } \\
\text { or block } \\
\text { structure }\end{array}$ \\
\hline $\begin{array}{l}\text { Semi-hard } \\
\text { rock }\end{array}$ & Medium-good & Sandstone Group & $15.4 \sim 33.4$ & Anding, Zhiluo and Yan'an & $\begin{array}{l}\text { block } \\
\text { structure }\end{array}$ \\
\hline
\end{tabular}

\section{Hydrogeological characteristics of shaft section}

\subsection{Quaternary aquifer}

The strata thickness of quaternary passed through by shaft is $19.68 \mathrm{~m}$, wherein the thickness of aqueous layer is $11.29 \mathrm{~m}$. It is composed of Holocene and Pleistocene aeolian sand Salawusu group Alluvial lake sediment. The lithology is the fine sand, loosing good permeability. According to drilling pumping test data, borehole water level elevation Quaternary taking the P19-hole Q+K11 pumping test is $1272.649 \mathrm{~m}$, the permeability coefficient taking the P23 drilling Quaternary pumping test is $3.39 \mathrm{~m} / \mathrm{d}$.

\subsection{Cretaceous aquifer}

The strata thickness of cretaceous passed through by shaft is $313.93 \mathrm{~m}$, wherein the aqueous layer thickness is $288.98 \mathrm{~m}$, the ratio is $92 \%$. The buried depth of Cretaceous is shallow. The upper is sandstone with the weak diagenesis, loosing structure and fracture development. And there is not 
stable impermeable layer with the overlying Quaternary pore aquifer. The seepage flow and runoff conditions are better. The aqueous medium porosity mainly large aquifer thickness and distribution are more stable. According to the drilling pumping test data, the borehole water level elevation takes the Cretaceous No.P19 hole Q+K11 and the pumping test value is $1272.649 \mathrm{~m}$. The permeability coefficient taking a value pumping test drilling Cretaceous No.P21 is $0.187 \mathrm{~m} / \mathrm{d}$.

\subsection{Anding formation in Jurassic}

The formation thickness of the wellbore is $37.19 \mathrm{~m}$,the thickness of the water bearing layer is $17.85 \mathrm{~m}$, the proportion is $48 \%$, and the lower part of Anding group. The lithology of the aquifer is a shallow gray sandstone, and the degree of consolidation of the aquifer is obviously improved compared with that of the Cretaceous strata. According to the drilling pumping test data, the hydrogeological parameters of the well bore Anding group were taken from the nearest P9 number to pumping test data of Anding group, and the water level elevation was $1251.91 \mathrm{~m}$, and the permeability coefficient was $0.0258 \mathrm{~m} / \mathrm{d}$.

\subsection{Zhiluo formation in Jurassic}

The thickness of Zhiluo formation is $229.83 \mathrm{~m}$, the thickness of the water bearing layer is $86.86 \mathrm{~m}$, the proportion is $38 \%$, and the water bearing layer is alternating with each other. The water bearing layer is relatively stable, and the lithology is mostly shallow gray fine-grained sandstone and medium grain sandstone. The degree of consolidation of the aquifer is high, and the water bearing medium is a crack. According to the drilling pumping test data, the water level of the Zhiluo is taken from the pumping test of the P25, and the permeability coefficient is ZL1, ZL2, ZL7, ZL8, P6, $\mathrm{P} 25$, and average value is also $0.0849 \mathrm{~m} / \mathrm{d}$.

\subsection{YanAn formation}

The Yanan formation thickness passed through by wellbore is $68.49 \mathrm{~m}$ and the thickness of water bearing layer is $23.89 \mathrm{~m}$, the proportion is $35 \%$. And the water bearing layer is alternating with each other. The water bearing layer is relatively stable, and the lithology is mostly shallow gray fine-grained sandstone and medium grained sandstone. With the depth increasing, the degree of aquifer consolidation is further strengthened. According to the borehole pumping test data, the wellbore hydro geological parameters of Yanan formation are taken from the pumping test data of the P23, and the water level is $1233.62 \mathrm{~m}$, and the permeability coefficient is $0.0529 \mathrm{~m} / \mathrm{d}$.

\subsection{Isolation and development characteristics}

(1) Development characteristics of the Quaternary and Cretaceous aquifer.

The shaft is covered by the aeolian sand and sandy clay layer of quaternary formation, not very closed to Cretaceous unconformity. The sandy clay layer is at the bottom of Quaternary with the thickness of $8.39 \mathrm{~m}$, brown color, loose structure, lens shaped. It cannot enough to constitute the steady water-resisting layer. The Quaternary groundwater and Cretaceous groundwater aquifers constitute a unified water bearing bed.

(2) Development characteristics of Cretaceous and Jurassic.

There is no integrated contact between the Cretaceous and the lower Jurassic, and there is no separation between the Cretaceous and the bottom of the Cretaceous, and the thickness of sandy mudstone in the top of Anding formation is $19.34 \mathrm{~m}$. Aquiclude entire mine development, more stable, just in the thickness difference, the average thickness is $16.11 \mathrm{~m}$, separated water performance is good, can be regarded as can play to resistance to the action of water stabilized aquiclude

\subsection{Characteristics of groundwater flow field}

In the northeast direction of coal field is the external northeast Hailiutu River and Yuxi River Watershed of grade 4, in the southwest is the peripheral Hailiutu river discharge points within the 
scope of mine. The groundwater levels in each segment are higher in the northeast, southwest low, groundwater flow field by restricting the excretion of datum, accept meteoric water vertical infiltration recharge after from northeast to southwest direction of run off.

\section{Wellbore inflow prediction}

The narrow horizontal catchment corridor method is adopted in the water inflow prediction. Due to in the excavation processing of wellbore, support and excavation is at the same time, so the single layer inflow is only predicted in the shaft excavation process.

The calculation formula of horizontal narrow catchment corridor as follows:

Diving: $\mathrm{Q}=\mathrm{BK}(2 \mathrm{H}-\mathrm{S}) \mathrm{S} / \mathrm{R}(R=2 S \sqrt{H K})$

Pressure to turn no pressure water: $\mathrm{Q}=\mathrm{BK}[(2 \mathrm{H}-\mathrm{M}) \mathrm{M}-\mathrm{h} 02] / \mathrm{R}(R=10 S \sqrt{K})$

B-Inlet length, m;

$\mathrm{H}$-The thickness of the diving layer or the pressure head height, $\mathrm{m}$;

M-Confined aquifer thickness, m;

h0-Residual water column height, m;

K-Permeability coefficient, $\mathrm{m} / \mathrm{d}$;

S-Deep water level, m;

R-Influence radius, m;

Q-Wellbore inflow, m3/d.

The wellbore parameters have the corresponding formula, the results are shown in table 2 . From the results, it can be seen that the shaft length in incline above $1083.35 \mathrm{~m}$ wells containing water gushing amount is larger, in 1083.35 1379.03m well section of the aquifer water inflow is medium, below $1379.03 \mathrm{~m}$ well the aquifer water gushing quantity is small.

Table 2 The main inclined shaft water inflow prediction parameters and calculation results

\begin{tabular}{cc}
\hline Aquifer & Water inflow prediction results $/ \mathrm{m}^{3} / \mathrm{d}$ \\
\hline quaternary formation & 40.024 \\
Luohe group & 191.078 \\
Anding group & 1.717 \\
Zhiluo group & 10.204 \\
Yanan group & 2.31 \\
Summation & 245.333 \\
\hline
\end{tabular}

\section{The solution of shaft construction}

(1) The water content of the quaternary aquifer is from medium to strong. Between 0 and 102.48 meters, the slope is the opened channel excavation section. The reasonable layout of hydrophobic holes in the water bearing layer is suggested to carry out the Landing water in advance, so that the water level fell to the bottom of the rockshaft bottom is $5 \mathrm{~m}$.

(2) The rockshaft passes through the Cretaceous well section that its dip length ranges from 102.48

to $1083.35 \mathrm{~m}$. Here the rock has the poor consolidation, the loose structure and the Low mechanical strength. The rock belongs to the extremely weak rock which has poor quality of rock mass and larger water gushing amount from the aquifer. So the normal excavation will cause considerable damage to the rock erosion. It is suggested that the freezing method or other special process is used in this section.

(3) The rockshaft passes through the Cretaceous well section that its dip length is 1083.35 
$1379.03 \mathrm{~m}$.Here the rock mass quality is mainly medium. But its integrity is poor and the compressive strength of the rock mass is small. Water gushing amount from the aquifer is general. So recommend the use of grouting construction method. At the same time, a lot should be done to achieve the Simultaneous driving and drainage work and the roof support work.

(4) The well section between 1379.03 and $2765.86 \mathrm{~m}$ is Jurassic well section which is anti-excavated. Major Rock mass saturated compressive strength ranges from 15 to $30 \mathrm{MPa}$. The integrity of rock mass is generally good. And the quality of rock mass is medium. Water gushing amount from the aquifer is relatively small. So Normal driving can be done. But a lot should be done to achieve the simultaneous driving and drainage work and the roof support work. However, compressive strength of the Mudstone section which is passed through by the rockshaft is relatively lower than the upper and the lower rock mass. And in the section, the quality of the rock mass is relatively poor. So during the processing of excavation, it should be paid attention to the varied strength in the different rock mass.

\section{The conclusion}

Through the carefully analysis and Research on the exploration report and the compilation of the drilling parameters which are completed ago. The detailed geological features, the engineering geological and the hydro geological characteristics of the rockshaft are understood. The horizontal narrow catchment corridor method is adopted to predict the Single layer's water gushing amount. According to the analysis comprehensively of hydrogeology and engineering geology characteristics of each layer, the optimal scheme of slope excavating was established.

\section{References}

[1] Guangcai Huo, Xueyu Lin, Xiaosi Su, etc. Study on groundwater system in Ordos Creta ceous Basin[J]Journal of Jilin University(Earth Science Edition),36(03):391-398(2006)

[2]Guangcai Hou, Deqian Wang, Lihe Yin. Structural analysis of groundwater system in Ord os Basin and its exploration thinking[A]. Xi'an: Shaanxi science and Technology Press (200 4)

[3]Zongbin Liu, the geological report by checking the inspection hole in the shaft of the D a Hai Ze mine[R].Xi'an: Shaanxi nuclear industrial geological survey(2011)

[4]Wei Song, Da Hai Ze mine feasibility study report[R] Xi'an:Xi'an Coal Design Engineeri ng Limited Liability Company (2013)

[5]Chunxu Li, Da Hai Ze coal mine first mining area hydro geological supplement explorati on report[R]. Handan, China General Administration of coal geology Hue Shang hydro geol ogical exploration engineering company (2014)

[6]China Coal Construction Association.GB50511-2010.coal mine well lane engineering const ruction standard[S].Beijing: People's press (2011)

[7]National Technical Supervision Bureau of.GB/T12719-91.mining area hydrogeological engi neering geological exploration specification[S](1991)

[8]Ministry of construction of the people's Republic of China.GB50218-94.Engineering rock mass classification standard[S](1994) 